\title{
Estimation of Global Solar Radiation from Temperature Extremes: A Case Study of Hebron City, Palestine
}

\author{
Husain Alsamamra \\ Physics Department, Al-Quds University, Jerusalem, Palestine
}

Email address:

hsamamra@staff.alquds.edu

\section{To cite this article:}

Husain Alsamamra. Estimation of Global Solar Radiation from Temperature Extremes: A Case Study of Hebron City, Palestine. Journal of Energy and Natural Resources. Vol. 8, No. 1, 2019, pp. 1-5. doi: 10.11648/j.jenr.20190801.11

Received: December 21, 2018; Accepted: January 9, 2019; Published: February 13, 2019

\begin{abstract}
Solar radiation is the main energy source for mankind and an accurate data of solar radiation levels for a particular location is vital for the optimum operation of solar energy transducers such as photovoltaic cells and solar thermal collectors. This study aimed to calibrate some of the existing models in the literature for estimating daily global solar radiation parameter using available measured records of air temperature extremes and new models were developed based on maximum and minimum air temperatures. Applicability of the Hargreaves model, Allen model, Bristow-Campbell model and Chen et al. model were evaluated for computing the global solar radiation for Hebron city in Palestine. Estimated values were compared with measured values in terms of the coefficient of determination $\left(\mathrm{R}^{2}\right)$ and root mean square error (RMSE). All models provide good estimates when compared to the accurate values with $\mathrm{R}^{2} 0.9226$ (Bristow-Campbell model) to 0.9547 (Chen et al. model), while the proposed model provides a value of 0.9632 . The RMSE value ranges from 0.7632 for Chen et al. model to 0.9211 for Bristow-Campbell model, however a lower value $(0.7118)$ for the proposed model. This study found that the proposed model estimates global solar radiation at the location of study better than the other models.
\end{abstract}

Keywords: Solar Radiation, Air Temperature Extremes, Model Comparison, Model Validation

\section{Introduction}

Solar radiation at the Earth's surface is the principal and fundamental energy for many physical, chemical and biological processes, such as crop growth and plant photosynthesis, and it is also an essential and important variable to many simulation models studies, such as agriculture, environment, hydrology, meteorology and ecology. Hence, an accurate record of solar radiation is of vital importance [1-2].

However, solar radiation data is not as readily available as air temperature and precipitation data [3-5]. Even at stations where solar radiation is observed there could be many days when solar radiation data are missing or lie outside the expected range due to equipment failure and other problems [6]. These problems could be one of many: calibration problems, problems with dirt on the sensor, accumulated water, shading of the sensor by masts, etc.

The demand for suitable radiation data has in turn led researchers to develop a number of predictive methods for estimating solar radiation. Some of these methods include estimating solar radiation from other available meteorological observations [7-14]. However, those are based on empirical relationships using commonly measured meteorological elements such as air temperature data are attractive due to lower data requirement and computation costs [3, 15]. In addition, the temperature-based solar radiation model can reduce the uncertainty of the crop simulations [1, 11, 16-17].

Although air temperature-based empirical models are founded on theoretical concepts for energy exchange on the surface boundary layer [18]. These models are based on the assumptions that (a) clear skies will increase the daily maximum temperature because of the greater short wave radiation input, while resulting in decreased minimum air temperature due to reduced long wave emission from the atmosphere; and (b) cloudy conditions will decrease the daily maximum air temperature due to reduced air transmissivity, while resulting in increased minimum air temperature due to increased long wave radiation from the clouds [19-21]. Therefore, estimating solar radiation using air temperature data is of vital importance and significance. 
Bristow and Campbell (1984) using this relationship estimated daily solar radiation using an exponential function of daily air temperature range $(\Delta T)[8]$. They were able to account for the variation of the in incoming daily solar radiation data at the site of interest. The Bristow and Campbell model has been modified by others for specific applications. For example, Donatelli and Marletto (1994) and Donatelli and Campbell (1998) included a summer night air temperature factor to improve underestimation of predicted values during the summer [22-23]; Hargreaves et al. (1985) also developed a simple linear relationship between daily air temperature range and clearness index [9]. Hunt et al. (1998), based on the evaluation of five solar radiation models, found best estimates in a model with multiple-linear relationship between daily incoming solar radiation, and air temperature and precipitation [1]. Mahmoud and Hubbard (2002) also found more stable estimations of daily incoming solar radiation from clear-sky solar radiation and daily air temperature range compared with the Bristow and Campbell model [24].

Therefore, the objective of this study is the validation of various models in the literature; mainly those use the difference between maximum, minimum and average air temperatures, to estimate daily total global radiation in Hebron city, Palestine. Also, this study suggests a new estimation model for the prediction of the solar radiation. This work is organized as follows: In section II i will discuss the methodology used, in section III provides the models used in this study, in section $\mathrm{V}$ the discussion of the results and finally section VI provides the conclusions.

\section{Methodology}

\section{Site Study and Data}

Hebron City is a busy hub of west bank trade located in the southern part of west bank in Palestine at latitude of $31^{\circ} 57^{\prime}$ $\mathrm{N}$, it lies 950 meters above sea level and its climate is hot in summer and cold in winter. Also, it receives a large quantity of solar radiation, especially in summer [9]. The data employed in this work were supplied by the Palestinian meteorological office. A radiometric station was established at the Hebron city municipality (1000 m above sea level). The meteorological dataset is selected on a daily basis. These meteorological data belong to the period between January 2015 and December 2017. Maximum and minimum temperatures, daily total global solar radiation, and daily average temperature values were taken from meteorological station. Extraterrestrial solar radiation values were obtained by calculation. With the help of this data obtained from meteorological station, the models in the literature have been calibrated and new model have been developed.

Calculations of Daily Extraterrestrial Solar Radiation

The plane of rotation of the earth around the sun is called the ecliptic plane. The rotation axis of the earth is called polar axis. The earth's rotation and the position of the earth axis causes diurnal and seasonal changes in solar radiation. The angle between the sun and the equatorial plane of the earth is different in every day of the year. This angle is called the solar declination angle; $\delta$ [25]. The solar declination angle's mathematical formula can be seen in equation $1 . \mathrm{J}$ is the calendar day in this equation with $\mathrm{J}=1$ on January 1 and $\mathrm{J}=365$ (or 366 during leap years) on December31 [26-28].

$$
\sin \delta=0.39785 * \sin [278.97+0.9856 J+1.9165 * \sin (356.6+0.9856 J)]
$$

Daily extraterrestrial solar radiation as provided by Iqbal (1983) as shown in equation 2.

$$
H_{0}=\frac{24}{\pi} * I_{s c} * E_{0} * \sin \varphi * \sin \delta *\left[\left(\frac{\pi}{180}\right) * w_{s}-\tan _{s}\right]
$$

Where $I_{s c}$ is the solar constant and it is equal to 4.921 $\mathrm{MJ} /$ day. $\mathrm{m}^{2}$ [27], $\mathrm{w}_{\mathrm{s}}$ is the sunrise hour angle (eq. 3), $\varphi$ is the latitude of the site and $\mathrm{E}_{0}$ (eq. 4 ) is the eccentricity correction factor of the earth's orbit.

$$
\begin{gathered}
w_{s}=\cos ^{-1}(-\tan \varphi * \tan \delta) \\
E_{0}=1+-0.033 * \cos \left(\frac{2 \pi * J}{365}\right)
\end{gathered}
$$

\section{Model Description}

Recent studies on temperature-based models in the literature $[10,14]$ assume that solar radiation is a function of the difference between daily maximum and minimum air temperature. This is based on the assumption that the difference generally indicates daily cloudiness. Clear skies corresponds to higher solar radiations levels at the earth surface and cloudy skies corresponds to lower solar radiation levels. The regression models proposed in the literature and used in this study as well as the proposed model are listed in Table 1.

Table 1. Regression models used in the study.

\begin{tabular}{lll}
\hline Model No. & Regression Equation & Source \\
\hline 1 & $\frac{H}{H_{0}}=a *\left(T_{\max }-T_{\min }\right)^{0.5}+b$ & Hargreaves (1985) \\
2 & $\frac{H}{H_{0}}=a *\left(T_{\max }-T_{\min }\right)^{0.5}$ & Allen (1997) \\
3 & $\frac{H}{H_{0}}=a *\left[1-\exp \left(-b \Delta T^{c}\right)\right]$ & Bristow and Campbell (1984) \\
4 & $\frac{H}{H_{0}}=a * \ln \left(T_{\max }-T_{\min }\right)+b$ & Chen at al. (2014) \\
5 & $\frac{H}{H_{0}}=a * \ln \left(T_{\max }-T_{\min }\right)+b\left(\frac{T_{\min }}{T_{\max }}\right)^{2}$ & Proposed model \\
\hline
\end{tabular}

All models were used in this study considering the temperature extremes as the principle input in order to 
estimate global solar radiation at the study site. However, the parameters and accuracy of these empirical formulas need to be calibrated and tested locally. The empirical coefficients for each model are obtained from the regression equation and then an assessment criteria was used to compare the results obtained.

\section{Assessment Criteria}

Most studies evaluating the performance of solar radiation models have traditionally used coefficient of determination $\left(\mathrm{R}^{2}\right)$, root mean square error (RMSE) and/or model bias to assess model suitability and comparison [1, 3, 24, 29-31]. The test on RMSE provides information on the short-term performance of the model as it follows a term-by term comparison of the actual deviation between calculated and measured value [17]. The test of MAPE provides information on the long term performance of the models studied. Also, the coefficient of determination was used to measure the relation between measured and estimated global solar radiation.

\section{Results and Discussion}

For many developing countries solar radiation measurements are not easily available due to the incapability to afford the measuring equipment's and techniques involved. It is therefore important to consider methods of estimating the solar radiation based on the readily available meteorological parameters. In this work temperature extremes were used to evaluate the empirical formulas listed in table 1 in order to estimate global solar radiation in Hebron city, Palestine.

The regression constants $\mathrm{a}, \mathrm{b}$ and $\mathrm{c}$ are reported for the four models in Table 2. The regression coefficient provides a valuable value for all models with slightly higher values for Chen et al. and the proposed models. The monthly values of RMSE and MAPE between measures and estimated global solar radiation data for the four models are calculated and presented in Table 3.

Table 2. Regression coefficients of the five models for Hebron city.

\begin{tabular}{llllll}
\hline Model No. & $\mathbf{R}^{2}$ & $\mathbf{a}$ & $\mathbf{b}$ & c & Source \\
\hline 1 & 0.9324 & 0.1622 & -0.0176 & - & Hargreaves (1985) \\
2 & 0.9331 & 0.1384 & - & - & Allen (1997) \\
3 & 0.9226 & 1.751 & 0.9416 & 0.0620 & Bristow and Campbell (1984) \\
4 & 0.9547 & 0.3186 & -0.1152 & - & Chen at al. (2014) \\
5 & 0.9632 & 0.2314 & 0.04170 & - & Proposed model \\
\hline
\end{tabular}

Table 3. The values of RMSE and MAPE of the five models.

\begin{tabular}{llll}
\hline Model No. & RMSE $\left(\mathbf{M J} / \mathbf{m}^{2}\right.$.day) & MAPE (\%) & Source \\
\hline 1 & 0.8874 & 9.1145 & Hargreaves $(1985)$ \\
2 & 0.8225 & 8.3620 & Allen (1997) \\
3 & 0.9211 & 9.4426 & Bristow and Campbell (1984) \\
4 & 0.7632 & 0.6625 & Chen at al. (2014) \\
5 & 0.7118 & 0.5080 & Proposed model \\
\hline
\end{tabular}

The statistical validation presented in table 3 provides that best performance of the proposed model with RMSE value $0.7118 \mathrm{MJm}^{-2} \mathrm{day}^{-1}$ and MAPE value 0.5080 , Chen et al. (2014) model provides a close values of RMSE and MAPE to the proposed model. The worst values were obtained for the model of Bristow and Campbell (1984). As a result, the proposed model was found to be more accurate than the other models used in this study to estimate global solar radiation by using air temperature extremes in Hebron city.

Table 4 presents the measured and calculated values of the monthly average of daily global solar radiation on a horizontal surface for Hebron city. It can be concluded that the calculated values from the five models are in a good agreement with the measured data. However, Hargreaves (1985) provides an under estimation of the global solar radiation values, whereas Allen (1997), Bristow and Campbell (1984) and the proposed model provide an overestimation of global solar radiation values, while Chen et al. (2014) model provides an under estimation in summer months (May to September) and over estimation of the other months of the year. Overall, it was found that the proposed model provides more accurate estimates as compared with the measured global solar radiation in winter months (October to April) while Chen et al. (2014) model provides a closer estimated values to the measured in summer months.

Table 4. The comparison between measured and estimated values of the monthly average daily global solar radiation $\left(M J / m^{2}\right)$ for the models.

\begin{tabular}{|c|c|c|c|c|c|c|}
\hline Month & Measured & Hargreaves (1985) & Allen (1997) & Bristow and Campbell (1984) & Chen at al. (2014) & Proposed model \\
\hline JAN & 11.8271 & 11.6032 & 12.5234 & 12.9343 & 12.3072 & 12.0211 \\
\hline FEB & 16.5234 & 15.4113 & 17.4617 & 17.0930 & 17.2306 & 16.9734 \\
\hline MAR & 20.1504 & 19.6261 & 21.8422 & 21.4053 & 20.9850 & 20.6352 \\
\hline APR & 25.1654 & 24.0842 & 26.2091 & 26.2119 & 25.7509 & 25.4094 \\
\hline MAY & 29.8173 & 28.3320 & 30.4025 & 30.8225 & 29.4063 & 30.3046 \\
\hline JUN & 30.9034 & 29.1268 & 32.0919 & 32.3233 & 30.5226 & 31.4461 \\
\hline JUL & 31.0713 & 30.1901 & 32.9791 & 33.0861 & 30.0823 & 32.0318 \\
\hline
\end{tabular}




\begin{tabular}{lllllll}
\hline Month & Measured & Hargreaves (1985) & Allen (1997) & Bristow and Campbell (1984) & Chen at al. (2014) & Proposed model \\
\hline AUG & 28.7423 & 27.7342 & 30.0563 & 29.9724 & 28.1532 & 29.9164 \\
SEP & 23.9841 & 22.2402 & 25.0984 & 24.9315 & 23.4205 & 24.7057 \\
OCT & 18.0949 & 17.1826 & 19.6132 & 19.3478 & 18.9521 & 18.6361 \\
NOV & 14.0923 & 13.0611 & 15.7328 & 15.5546 & 14.8381 & 14.5064 \\
DEC & 12.0553 & 11.2203 & 13.9117 & 13.7443 & 12.9066 & 12.4426 \\
\hline
\end{tabular}

\section{Conclusion}

Empirical models are usable tools to estimate global solar radiation, if the radiation parameters are not available in the station. Main aim of this study is the estimation of the daily total solar global radiation values by using maximum and minimum daily air temperatures. Four models in the literature and a proposed model have been employed for estimating global solar radiation for Hebron city. The differences between the results of the different models are very clear in terms of $\mathrm{R}^{2}$ and RMSE values. The proposed model is better than the other models according to $\mathrm{R}^{2}$ and RMSE, and has the best performance based on the measured data at one station in Hebron city. It can be recommended to use the proposed equation.

\section{Acknowledgements}

We would like to acknowledge the Palestinian meteorological stations network office for their kindly help in providing the data.

\section{References}

[1] L. A. Hunt, L. Kuchar and C. J. Swanton, "Estimation of solar radiation for use in crop modelling", Agriculture and Forest Meteorology, vol. 98, pp. 293-300, 1998.

[2] C. W. Richardson, "Stochastic simulation of daily precipitation, temperature, and solar radiation", Water Resource Research, vol.17, pp. 182-190, 1981.

[3] X. Liu, X. Mei, Y. Li, Q. Wang, Y. Zhang and J. R. Porter, "Variation in reference crop evapotranspiration caused by the Angström-Prescott coefficient: locally calibrated versus the FAO recommended", Agriculture and Water Manage, vol. 96, pp. 1137-1145, 2009

[4] A. Weiss, and C. J. Hays, "Simulation of daily solar irradiance", Agriculture and Forest Meteorology, vol.123, pp.187-199, 2004.

[5] G. Hoogenboom, "Estimation of solar radiation based on air temperature and application with the DSSAT v4.5 peanut and rice simulation models in Thailand", Agriculture and Forest Meteorology, vol. 180, pp.182-193, 2013.

[6] J. C. Cao and S. H. Cao, "Study of forecasting solar irradiance using neural networks with preprocessing sample data by wavelet analysis" Energy, vol.31, no.15, pp. 3435-3445, 2006.

[7] A. Angstrom, "Solar and terrestrial radiation", Quarterly journal of the Royal Meteorological Society, vol. 50, pp. 121- 126, 1924.

[8] K. L. Bristow and G. S. Campbell, "On the relationship between incoming solar radiation and daily maximum and minimum temperature" Agriculture and Forest. Meteorology, vol. 31, pp. 159-166, 1984.

[9] G. H. Hargreaves, (1994). "Simplified coefficients for estimating monthly solar radiation in North America and Europe", Utah State University, Logan, Utah.

[10] J. Liu, H. W. Linderholm, D. Chen, Q. Yu, D. Wu, S. Haginoya, "Observation and calculation of solar radiation on the Tibetan Plateau", Energy Conversion and Management, vol. 57, pp. 23-32, 2012.

[11] M. Rivington, K. B. Matthews, G. Bellocchi, K. Buchan, "Evaluating uncertainty introduced to process-based simulation model estimates by alternative sources of meteorological data", Agriculture Systems, vol. 88, pp.451471, 2006.

[12] P. E. Thorton and S. W. Running, "An improved algorithm for estimating daily solar radiation from measurements of temperature, humidity, and precipitation" Agriculture and Forest. Meteorology, vol. 93, 211-228, 1999.

[13] T. Mavromatis, "Estimation of solar radiation and its application to crop simulation models in Greece", Climate Research, vol. 36, pp.219-230, 2008.

[14] F. Meza and E. Varas, "Estimation of mean monthly solar global radiation as a function of temperature", Agriculture and Forest. Meteorology, vol. 100, pp. 231-241, 2000.

[15] X. Liu, X. Mei, Y. Li, Q. Wang, R. J. Jensen, Y. Zhang, J. R. Porter, "Evaluation of temperature-based global solar radiation models in Agriculture and Forest. Meteorology, vol. 149, no.9, pp. 1433-1446, 2009b.

[16] M. G. Abraha and M. J. Savage, "Comparison of estimates of daily solar radiation from air temperature range for application in crop simulations" Agriculture and Forest. Meteorology, vol.148, no.3, pp. 401-416, 2008.

[17] Alsamamra H, J. A, Ruiz-Arias, D. Pozo-Vazquez, J. TovarPescador, "Acomaprative study of ordinary and residual kriging techniques for mapping global solar radiation over southern Spain", Agriculture and Forest. Meteorology, vol. 149, no. 8, pp. 1343-1357, 2009

[18] D. G. Goodin, J. M. Hutchinson, R. L. Vanderlip, M. C Knapp, "Estimating solar irradiance for crop modeling using daily air temperature data" Agronomy Journal, vol. 91, pp.845-851, 1999.

[19] R. G. Allen, "Self-calibrating method for estimating solar radiation from air temperature". Journal of Hydrologic Engineering, vol.. 2, pp.56-67, 1997.

[20] J. Almorox, M. Bocco, E. Willington, "Estimation of daily global solar radiation from measured temperatures at Cañada de Luque, Có rdoba, Argentina. Renew Energy, vol.. 60, pp.382-387, 2013.

[21] M. Donatelli and G. S. Campbell, "A simple model to estimate global solar radiation", The 5th European Society of Agronomy Congress. Nitra, Slovak Republic, 1998. 
[22] M. Donatelli, and V. Marletto, "Estimating surface solar radiation by means of air temperature", In Proceedings of European Society. for Agronomy Congress, 3rd, AbanoPadova, Italy. 18-22 Sept. The Padova Univ., Padova, Italy. pp. 352-353, 1994.

[23] M. Donatelli and G. S. Campbell, "A simple model to estimate global solar radiation", In Proc. ESA Cong., 5th, Vol. 2, Nitra, Slovak Republic. 28 June-2 July. The Slovak Agric. Univ., Nitra, Slovak Republic. pp. 133-134, 1998.

[24] R. Mahmood, and K. G. Hubbard, "Effect of time of temperature and estimation of daily solar radiation for the Northern Great Plains", USA Agronomy journal, vol. 94, pp.723-733, 2002.

[25] M. Iqbal, (1983). "An Introduction to Solar Radiation", Academic Press, Toronto.

[26] G. S. Campbell, J. M. Norman, "An introduction to environmental biophysics", Springer Science \& Business Media, 1998.
[27] J. Awsthi and K. N. Poudyal, "Estimation of global solar radiation using empirical model on meteorological parameters at Simara airport, Bara, Nepal", Journal of the institute of engineering, vol. 14, pp143-150, 2018.

[28] Q. Zhang, N. Cui, Y. Feng, Y. Jia, Z. Li and D. Gong, "Comparative analysis of global solar radiation models in different regions of China", Advances in meteorology, vol. 11, pp. 1-21. 2018.

[29] H. O. Menges, C. Ertekin, M. H. Sonmete, "Evaluation of global solar radiation models for Konya, Turkey", Energy Conversion and Management, vol.47, no.18, pp. 3149-3173, 2006.

[30] R. Chen, K. Ersi, J. Yang, S. Lu, W. Zhao, "Validation of five global radiation models with measured daily data in China", Energy Conversion and Management, vol.45, no.11, pp. 17591769,2004

[31] B. Abdedelhak, R. Souad, E. Najib , H. Abdelaziz, H. Faicel, Y. Farouk, "Estimation of global solar radiation using three simple methods", Energy Procedia, vol.42, pp. 406-415, 2013. 